\title{
Planktonic Aggregates of Staphylococcus aureus Protect against Common Antibiotics
}

\author{
Jakob Haaber ${ }^{1 \uparrow}$, Marianne Thorup Cohn ${ }^{1 \times \uparrow}$, Dorte Frees ${ }^{1}$, Thorbjørn Joest Andersen ${ }^{2}$, Hanne Ingmer ${ }^{1 *}$ \\ 1 Department of Veterinary Disease Biology, University of Copenhagen, Frederiksberg, Denmark, 2 Department of Geography and Geology, University of Copenhagen, \\ Copenhagen, Denmark
}

\begin{abstract}
Bacterial cells are mostly studied during planktonic growth although in their natural habitats they are often found in communities such as biofilms with dramatically different physiological properties. We have examined another type of community namely cellular aggregates observed in strains of the human pathogen Staphylococcus aureus. By laserdiffraction particle-size analysis (LDA) we show, for strains forming visible aggregates, that the aggregation starts already in the early exponential growth phase and proceeds until post-exponential phase where more than $90 \%$ of the population is part of the aggregate community. Similar to some types of biofilm, the structural component of $S$. aureus aggregates is the polysaccharide intercellular adhesin (PIA). Importantly, PIA production correlates with the level of aggregation whether altered through mutations or exposure to sub-inhibitory concentrations of selected antibiotics. While some properties of aggregates resemble those of biofilms including increased mutation frequency and survival during antibiotic treatment, aggregated cells displayed higher metabolic activity than planktonic cells or cells in biofilm. Thus, our data indicate that the properties of cells in aggregates differ in some aspects from those in biofilms. It is generally accepted that the biofilm life style protects pathogens against antibiotics and the hostile environment of the host. We speculate that in aggregate communities $S$. aureus increases its tolerance to hazardous environments and that the combination of a biofilm-like environment with mobility has substantial practical and clinical importance.
\end{abstract}

Citation: Haaber J, Cohn MT, Frees D, Andersen TJ, Ingmer H (2012) Planktonic Aggregates of Staphylococcus aureus Protect against Common Antibiotics. PLoS ONE 7(7): e41075. doi:10.1371/journal.pone.0041075

Editor: Michael Otto, National Institutes of Health, United States of America

Received January 28, 2012; Accepted June 17, 2012; Published July 18, 2012

Copyright: (c) 2012 Haaber et al. This is an open-access article distributed under the terms of the Creative Commons Attribution License, which permits unrestricted use, distribution, and reproduction in any medium, provided the original author and source are credited.

Funding: This work was supported by the Danish Reserch Council for Independent Research, grant number 274-08-0531, and the Lundbeck foundation, grant number R31-A2472. The funders had no role in study design, data collection and analysis, decision to publish, or preparation of the manuscript.

Competing Interests: The authors have declared that no competing interests exist.

*E-mail: hi@life.ku.dk

- These authors are joint first authors on this work.

a Current address: Novozymes A/S, Bagsvaerd, Denmark

\section{Introduction}

Many bacterial species can grow either in the form of dispersed single cells in liquid or as densely packed communities attached to solid surfaces. Researchers generally refer to the latter growth form as biofilm, which was defined by Costerton as "a structured community of cells enclosed in a self-produced polymeric matrix and adherent to an inert or living surface" [1]. The opportunistic, human pathogen, Staphylococcus aureus can establish itself in biofilms by colonizing natural body surfaces including lungs and heart valves as well as abiotic surfaces such as medical implants [2,3]. As cells present in biofilms are commonly protected against antibiotics and host defense molecules, biofilm formation has serious clinical consequences and is a significant contributor to the health care problems associated with $S$. aureus [4-6].

Staphylococcal biofilms contain several matrix components including extracellular DNA (eDNA), protein and polysaccharide $[2,7,8]$. In $S$. aureus, eDNA is released from dead cells by controlled cell lysis and the presence of eDNA is important in the very early establishment of the biofilm $[9,10]$. At this early stage, $S$. aureus cell surface proteins such as fibronectin and fibrinogen binding proteins and Protein A are also contributing [11,12]. The extracellular polysaccharide poly-ㅍ-acetyl-1,6-glucosamine
(PNAG) is often involved in biofilm formation and it is the most characterized component of the biofilm matrix. PNAG is synthesized by the products of the polysaccharide intercellular adhesin (PIA) locus, icaADBC [13] and mediates adhesion to both living and artificial surfaces [14,15]. The ica operon is present in many clinical $S$. aureus strains and its expression has been shown to be strongly induced in a device-related animal model, underscoring the importance of biofilms during infection [16].

During establishment of an infection, formation of biofilm may be seen as a survival strategy against host defenses and antimicrobial therapy. It is well accepted that biofilms protect the embedded cells against antimicrobial therapy [17-20] for example through reduced exposure to the antimicrobial compounds [21,22] or reduced metabolic activity that decreases susceptibility to a range of antibiotics [20]. However, although a biofilm can provide beneficial properties to the participating bacteria it also traps the cells in a sessile community with limited mobility. This limitation seems to have been circumvented by the human, opportunistic pathogen, Pseudomonas aeruginosa that upon growth in liquid culture forms large aggregates containing densely packed viable cells and eDNA [23]. The properties of $P$. aeruginosa cells present in aggregates resemble those of flow-cell biofilms by their slow growth rate, their capacity to survive otherwise lethal 
treatments with antibiotics and their ability to resist phagocytosis [24]. Interestingly, non-attached aggregates are also observed in the lungs of cystic fibrosis patients, in soft tissue fillers and in nonhealing wounds, indicating that they are of clinical relevance [2426].

Planktonic (non-attached) aggregation has also been observed for other bacterial species. In the food borne pathogen, Campylobacter jejuni, auto-aggregation is regularly observed but dispersal is promoted in mutants with disrupted stress response pathways $[27,28]$. Streptococcus pyogenes is another human pathogen that forms planktonic aggregates in liquid culture and this property is important for adherence, resistance to phagocytosis and virulence [29]. S. aureus is known to grow in small clusters of 520 cells but it also assembles in large aggregates that are visible to the naked eye and are observed in both laboratory and clinical settings [12,26]. While extensive research has focused on staphylococcal biofilms only little knowledge exists on the formation and properties of $S$. aureus planktonic aggregation.

Here, we characterize $S$. aureus aggregation and show that while aggregates share many of the properties of surface-bound biofilms, differences are also observed. In common to biofilms, the aggregation process is influenced by sub-lethal concentrations of antibiotics [30] and cells in aggregates are protected against several unrelated and clinically relevant antimicrobial compounds $[19,20]$. In contrast to biofilms, however, metabolic activity is high in aggregates. We speculate that aggregates provide bacteria with the benefits of a biofilm while maintaining mobility and that this combination may contribute to the difficulties of eradicating $S$. aureus infections.

\section{Results}

\section{Staphylococcus Aureus Aggregates in Solution}

Some strains of $S$. aureus are capable of forming large planktonic aggregates that are visible to the naked eye when grown under standard laboratory conditions [11,12,31]. From previous unpublished work we had noticed four strains with very different aggregation capabilities. These were two clinical isolates (15981 and SA564) and two laboratory strains (8325-4 and Newman), where 8325-4 and 15981 form visible planktonic aggregates, while Newman and SA564 do not (data not shown). With the aim of investigating this phenomenon in more detail, we applied scanning electron microscopy (SEM) to visualize aggregates in a postexponential culture of 8325-4 (Figure 1). Some aggregates were more than $0.5 \mathrm{~mm}$ of size and consisted of a large numbers of cells (Figure 1A). A closer look revealed pores and crevices in the compact mass of cells (Figure 1B) and at even higher magnification some cell-clusters were covered in a web-like structure as recently observed in biofilms of $P$. aeruginosa [32] while other clusters of cells remained un-covered (Figure $1 \mathrm{C}, \mathrm{D}$ ).

To quantify the extent of aggregation in liquid cultures of the four $S$. aureus strains, we monitored the formation of planktonic $S$. aureus aggregates using laser diffraction analysis (LDA) [23]. When grown to post exponential growth phase $\left(\mathrm{OD}_{600}=2\right)$ the majority of cells of strains 8325-4 and 15981 were assembled in particles of more than $6 \mu \mathrm{m}$ in diameter, the minimum size chosen to define an aggregate. For strains Newman and SA564 the average particle size was $1-2 \mu \mathrm{m}$ in diameter (Figure $2 \mathrm{~A}$ ) representing single and double cells as observed by microscopy. Further, the LDA analysis revealed that aggregate size varies between strains. For 8325-4 cultures two aggregate sizes of 100 and $800 \mu \mathrm{m}$ in diameter predominate while for strain 15981 the aggregates are approximate $60 \mu \mathrm{m}$ in diameter (Figure 2A).
To address the structural robustness of the $S$. aureus aggregates we applied increasing shear force as part of the LDA and found that with gradual steps of stirring (50-500 rpm) and pump speed (250-2500) no changes were observed in the size distribution until medium shear force was applied (stir $=300 \mathrm{rpm}$, pump $=1500 \mathrm{rpm}$ ). Even when exposed to maximum shear $($ stir $=500 \mathrm{rpm}, \quad$ pump $=2500 \mathrm{rpm})$, the aggregates were still surprisingly intact with a reduction in average aggregate size from $180 \mu \mathrm{m}$ to $45 \mu \mathrm{m}$ and maximum size from $480 \mu \mathrm{m}$ to $240 \mu \mathrm{m}$ (Figure $\mathrm{S} 1$ ). Thus, under the assayed conditions the $S$. aureus aggregates are structurally stable, which is in contrast to aggregates formed by $P$. aeruginosa that are readily dissolved by whirly mixing [24].

Aggregates are Formed already in the Exponential Phase

To address the temporal development of aggregate formation we monitored particle size of strains $8325-4$ and 15981 at various growth stages and found that while very little aggregation occurred at $\mathrm{OD}_{600}$ of 0.1 , already at $\mathrm{OD}_{600}$ of 0.5 around $50 \%$ of the cells were assembled into aggregates (Figure 2B). Thus, for the tested $S$. aureus strains, aggregation is not confined to the post-exponential growth phase but occurs already at mid-exponential phase. The size of the aggregates was two to three times larger for 8325-4 than for 15981. Interestingly though, when applying the $6 \mu \mathrm{m}$ threshold for defining aggregates, the distribution of cells in the aggregated versus dispersed fractions of cells was strikingly similar for strains 8325-4 and 15981 throughout the growth cycle (Figure 2B).

To address whether aggregates are formed by interconnected daughter cells that are not separated after cell division or from aggregation of single cells or smaller clusters we monitored aggregation of fluorescent and non-fluorescent, isogenic 8325-4 cells after mixing $(1: 1)$ at $\mathrm{OD}_{600}=0.01$ [33]. The results show that in the early growth stages $\left(\mathrm{OD}_{600}=0.01\right.$ to 0.1$)$ small grape-like clusters are formed by $\approx 10$ interconnected daughter cells (Figure 3A). At $\mathrm{OD}_{600}=0.1$ the clusters of different clonal origin begin to merge (Figure 3B) and from $\mathrm{OD}_{600}=0.5$ an increasing number of large aggregates are observed that are composed of both labeled and non-labeled cells (Figure 3C). Thus, our results suggest that the large multi-cellular aggregates observed in postexponential growth phase arise from small cell clusters that merge during exponential growth phase and end up glued together in large multi-cellular structures.

\section{Sub-inhibitory Concentrations of Antibiotics and Environmental Factors Influence Aggregation}

Bacterial pathogens may be exposed to sub-lethal concentrations of antibiotics as a consequence of uneven antibiotic distribution during antimicrobial therapy, inadequate use of antibiotics or from exposure to antimicrobials naturally produced in soil and water environments [34-36]. Notably, we observed that addition of sub-inhibitory concentrations $(1 / 25 \times \mathrm{MIC})$ of several clinically relevant antibiotics influenced the aggregation properties of the aggregating strains 8325-4 and 15981 (Figure 4). The RNA polymerase inhibitor rifampicin stimulated aggregation while the protein biosynthesis inhibitor erythromycin and the cell wall synthesis inhibitor cefuroxime reduced aggregation. Further we examined the aggregation ability in $43 \mathrm{~S}$. aureus strains from our culture collection comprising laboratory strains and clinical isolates. We found that while significant differences were observed between strains, exposure to either $2 \% \mathrm{NaCl}, 35 \mathrm{mM}$ glucose or reduced oxygen tension induced aggregation in all strains tested (data not shown) suggesting that the ability to aggregate is omnipresent in $S$. aureus. 

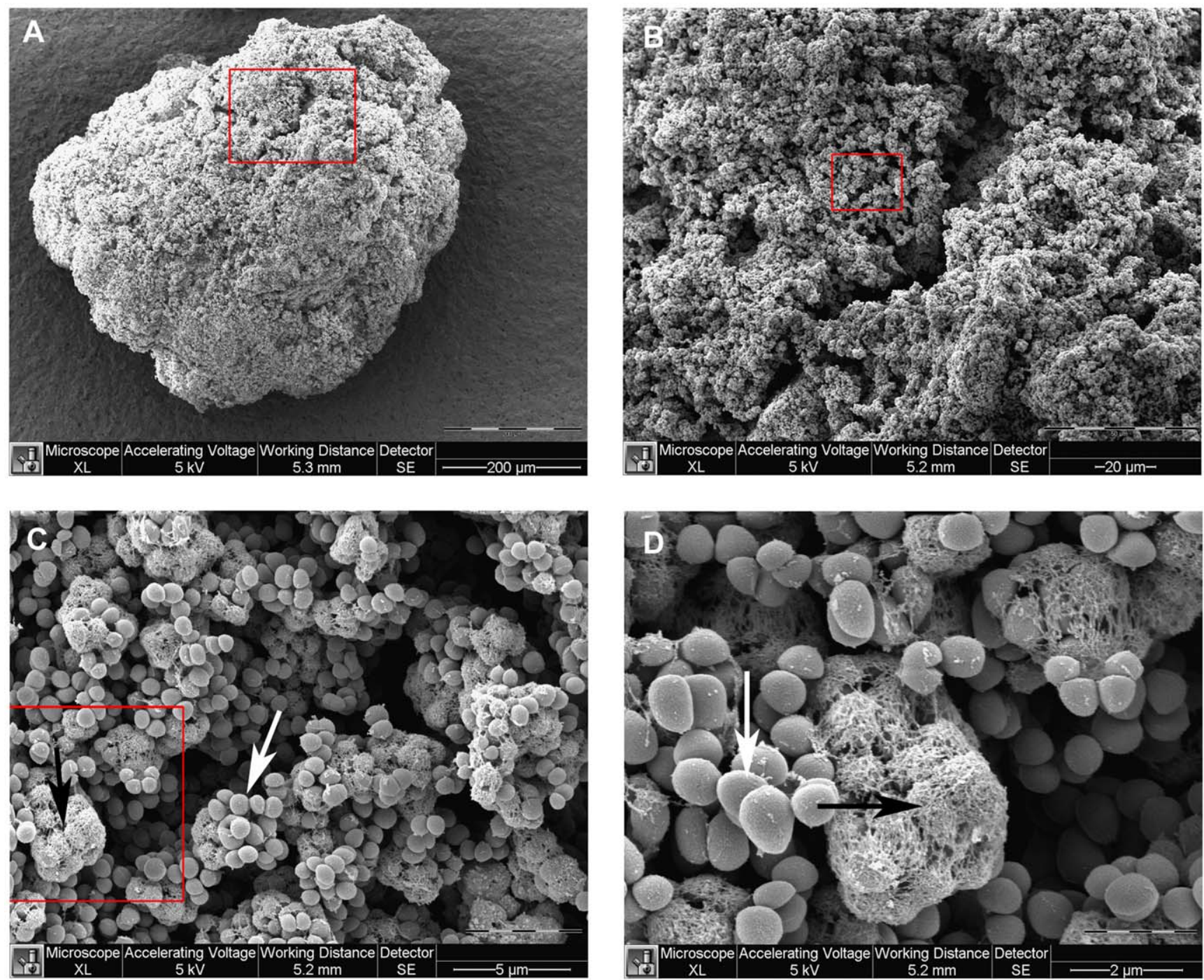

Figure 1. Aggregate visualized by SEM. Aggregates from a post-exponential 8325-4 culture were fixed and visualized using Scanning Electron Microscopy (SEM). Panels A-D represent increasing magnification and red squares indicate the area magnified in the following panel. Overview of an aggregate, which is visible to the naked eye (A). Zooming in reveals pores and crevices in a topographical landscape of aggregated clusters (B). At higher magnifications it is revealed that some clusters are embedded in a web-like matrix (black arrows) while some are not (white arrows) (C, D). doi:10.1371/journal.pone.0041075.g001

The Polysaccharide Intercellular Adhesion (PIA) Promotes

\section{Aggregate Formation}

The cellular level of the polysaccharide intercellular adhesin (PIA) produced by the enzymes encoded by the icaADBC operon has been noted to influence dispersed growth of staphylococci in liquid cultures $[31,37]$. To evaluate the contribution of PIA to aggregation in $S$. aureus, we examined aggregate formation in an isogenic ica mutant of 8325-4 during post-exponential growth. No visible aggregates were observed and using LDA we could verify that no particles larger than $6 \mu \mathrm{m}$ were present in the culture demonstrating that aggregates are not formed in the absence of PIA (Figure S2). In an isogenic ica mutant of 15981 aggregation was also abolished (data not shown).

To further investigate the composition of the extracellular matrix in S. aureus aggregates we examined the resistance to the action of either proteinase K, DNase or metaperiodate, which degrade protein, DNA and polysaccharide, respectively. Only the addition of metaperiodate resulted in disruption of aggregates
(Figure 5). This result indicates that extracellular polysaccharides form the major adhesive component of the aggregates thus supporting the genetic data stating the importance of the ica operon.

The central role of PIA polysaccharide was further confirmed by serological detection of PIA production in aggregating and nonaggregating strains. Here we observed a clear correlation between PIA production and aggregation (Figure 6A). Furthermore, analysis of the PIA level in 8325-4 cultures treated with antibiotics showed that rifampicin increased the cellular PIA level, while cefuroxime and erythromycin decreased PIA production (Figure 6B). The PIA levels correlated well with the level of aggregation of 8325-4 treated with these antibiotics (Figure 4). Collectively, these results indicate that the production of PIA is a major contributor to planktonic aggregate formation of $S$. aureus and that sub-inhibitory concentrations of antibiotics may affect aggregation, possibly through modulation of PIA production.

In addition to PIA other cellular components such as the fibronectin binding proteins have been reported to influence 
A
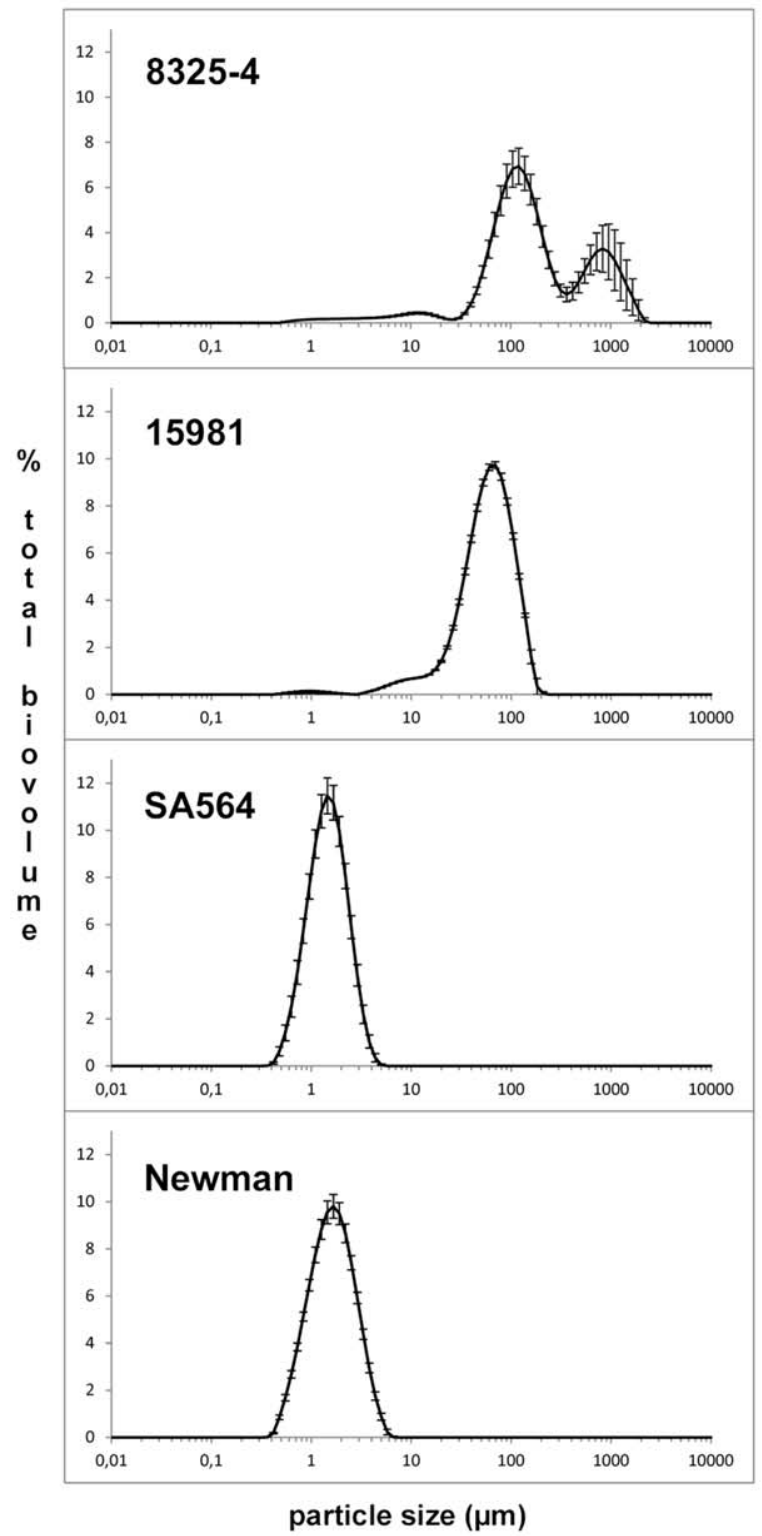

B
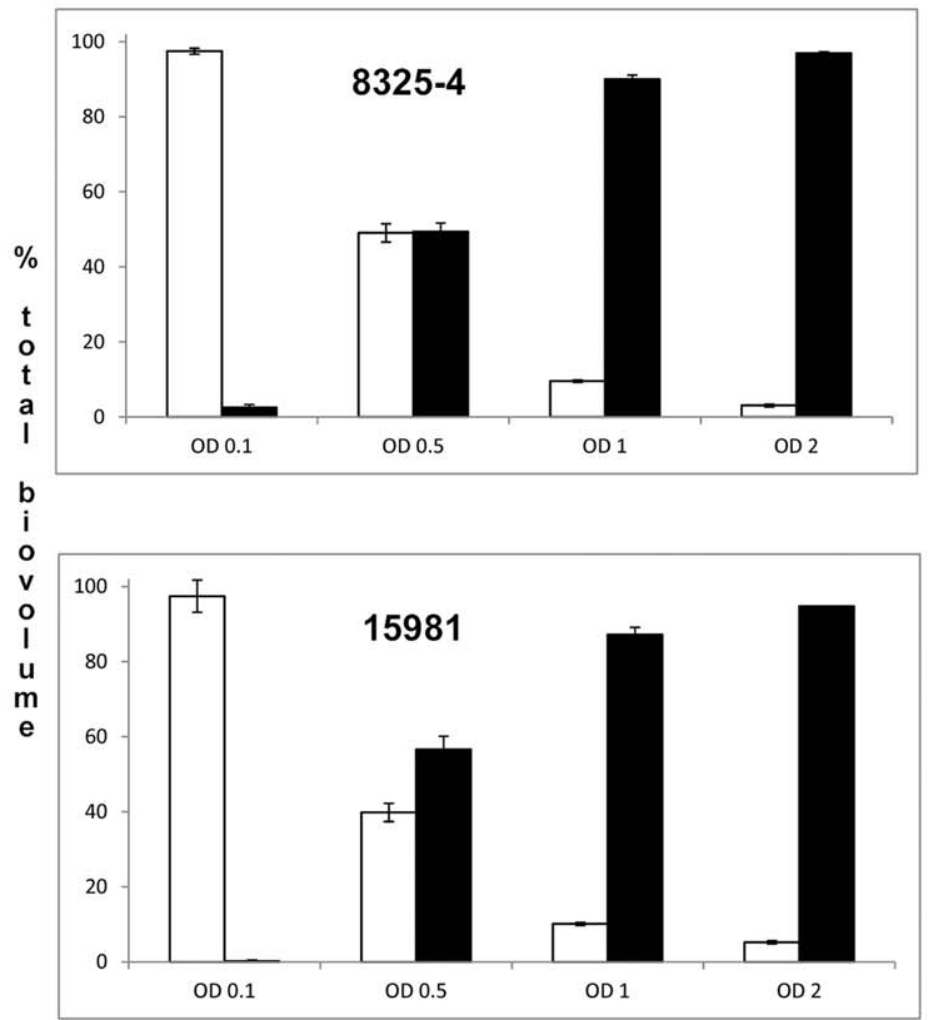

Optical density (OD) of population

Figure 2. Aggregate size distribution measured by LDA. Four different $S$. aureus strains were investigated for their level of aggregation in post-exponential growth phase $\left(\mathrm{OD}_{600}=2\right)(\mathrm{A})$. The two aggregating strains were followed through exponential growth and the percentage of cells in aggregates ( $>6 \mu \mathrm{m}$, solid bars) relative to the non-aggregating fraction (open bars) is shown (B). \% total biovolume is calculated as the percentage of cells of a given size relative to the total suspended cell mass. Error bars indicate standard deviation $(n=5)$.

doi:10.1371/journal.pone.0041075.g002

biofilm formation [11]. However inactivation of $f n b p A$, fnbpB and fnbp $A B$ in strain 8325-4 did not influence particle size when compared to wild type cells suggesting that these proteins do not contribute to $S$. aureus aggregation (Figure S2). In addition we examined aggregation in a mutant strain of 8325-4 lacking agr, the $S$. aureus quorum sensing locus that controls virulence gene expression and in SH1000, a Sigma B $\left(r s b U^{+}\right)$complemented strain of 8325-4. While both mutant strains are reported to be good biofilm formers $[15,25]$ they were essentially unable to aggregate (Figure S2). Thus, our data suggest that some elements of aggregation differ from biofilm formation and that the processes behind may not be identical.

Aggregation Increases Metabolic Activity and Mutation Frequency

Phenotypic properties of biofilm-associated cells vary from those of single cells in several ways including metabolic activity [6] and mutation frequency $[38,39]$. We investigated whether this is also the case for aggregated cells. The metabolic activity of cells correlates with the reduction of a tetrazolium salt (XTT) to the colored compound formazan [40,41]. When applying this colorimetric method to evaluate the metabolic activity of aggregated and planktonic cells, we surprisingly found that on average the metabolic activity of cells in aggregates was approximately 7 fold higher than in planktonic cells $(p<0.001$, Figure 7A). This is in contrast to what has been reported for 

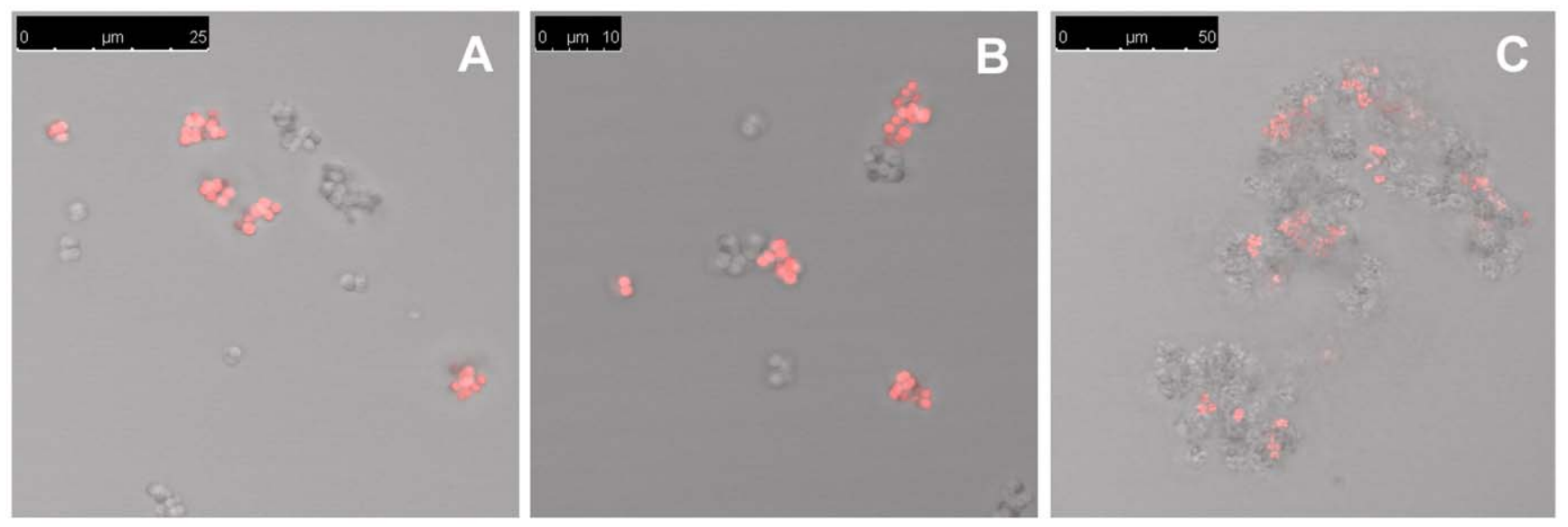

Figure 3. Kinetic of aggregate formation. $8325-4$ cells were mixed 1:1 with 8325-4 cells expressing YFP to $\mathrm{OD}_{600}$ of 0.01 and examined using CLSM every 30 min through a growth cycle. Small clusters of cells dominate until $\mathrm{OD}_{600}=0.1$ (A) at which time they start to fuse (B) and form large aggregates around $\mathrm{OD}_{600}=0.5$ (C). Note different sizes of scale bars. doi:10.1371/journal.pone.0041075.g003

biofilm associated cells, where oxygen and nutrient limitation results in low metabolic activity [20]. Accordingly, we saw approximately 4 fold lower metabolic activity in a biofilm compared to dispersed cells $(\mathrm{p}<0.001)$ (Figure S3). When comparing metabolic activity of aggregates with cells originating from aggregates disrupted by sonication, no differences were observed (data not shown, $\mathrm{p}=0.84$ ). Furthermore, when comparing isogenic ica mutants of both 8325-4 and 15981 to aggregates and dispersed cells, metabolic activity was significantly higher in the aggregates than in dispersed wild type and ica mutant cells (Figure S3, p <0.05). In biofilms, the metabolic activity is unevenly distributed depending on oxygen and nutrient availability [42]. CLSM of LIVE/DEAD stained aggregates revealed that analogous to biofilms, aggregates are unevenly composed of areas of cells with low metabolic activity surrounded by metabolically active cells (Figure 7B). Collectively, our results show that on average cells in aggregates are markedly more metabolically active compared to those in biofilms or planktonic cells.

Mutation frequency has previously been reported to be higher in biofilms compared to single cells $[38,39]$. We determined the mutation rate, calculated by the number of generated rifampicinresistant-mutants per total $\mathrm{CFU}$, and found that it was 2 fold greater in the aggregate fraction compared to the dispersed cell fraction (Figure S4, p=0.0015). Thus, aggregates resemble biofilms by having a slightly increased mutation frequency compared to planktonic cells.

\section{Aggregation Promotes Protection against Antibiotic Killing}

Interestingly, we noted that the biomass of dispersed cells increased during stationary phase compared to the aggregated fraction (data not shown) indicating that cells might detach from the aggregates to become dispersed as observed for $P$. aeruginosa when experiencing starvation [23]. Therefore, we used an experimental set up with antibiotic markers that enabled us to follow cells from the two fractions after antibiotic exposure. Aggregated and dispersed cells with different antibiotic markers were mixed and exposed to $25 \times \mathrm{MIC}$ of clinically relevant antibiotics with different cellular targets (kanamycin, ciprofloxacin, erythromycin and vancomycin). Importantly, antibiotic exposure mediated increased shedding of cells from the aggregate fraction to the dispersed fraction (data not shown, $\mathrm{p}<0.05$ ). Furthermore, we found that cells assembled in aggregates were protected against the lethality of antibiotics and survived significantly better $(p<0.05)$ compared to dispersed cells (Figure 8). For kanamycin there was a dramatic $(100 \times)$ increase of survival in the aggregated cells compared to dispersed cells, while for ciprofloxacin, vancomycin and erythromycin the increased survival was $30 \times, 14 \times$ and $8 \times$ higher, respectively (Figure 8). However, if aggregates were disrupted by sonication and the released cells were exposed to kanamycin, the protection was completely abolished and the susceptibility of the cells was comparable to the non-aggregated cell fraction (data not shown, $\mathrm{p}<0.01$ ). This is equivalent to observations in $P$. aeruginosa in which tobramycin regained its efficacy after disruption of the aggregates [24] and it indicates that protection against antibiotics in aggregates in these two species is mediated by a physical barrier provided by the aggregate matrix as also observed for flocculating yeast [43].

\section{Discussion}

The ability of Staphylococcus aureus to form biofilms on host tissues and medical implants is considered to be one of the most important traits contributing to the health care problems associated with the organism $[11,44,45]$. Recently it was proposed for another opportunistic pathogen, $P$. aeruginosa, that non-attached planktonic aggregates of cells may be considered dispersed biofilms and that these planktonic aggregates have the same protective properties as biofilms [24]. Sporadically, S. aureus has been reported to form planktonic aggregates under laboratory conditions [12,31] and in clinical infections $[26,46]$ but so far this property has received little attention.

We show here that the ability of $S$. aureus to form large planktonic aggregates is highly dependent on strain and growth conditions and is observed for both clinical and laboratory strains. The aggregation process starts already in the early exponential growth phase. At low cell densities $S$. aureus 8325-4 grows in clonal, structured populations of up to approx. 20 cells whereas at greater cell densities these structures merge into large aggregates measuring up to $1000 \mu \mathrm{m}$ in diameter.

The matrix component responsible for the extensive aggregation is a polysaccharide and is likely to be the extracellular polysaccharide PIA, as Western blot analysis correlated the level of aggregation to PIA production and absence of the ica operon (encoding the PIA producing enzymes) completely abolished 


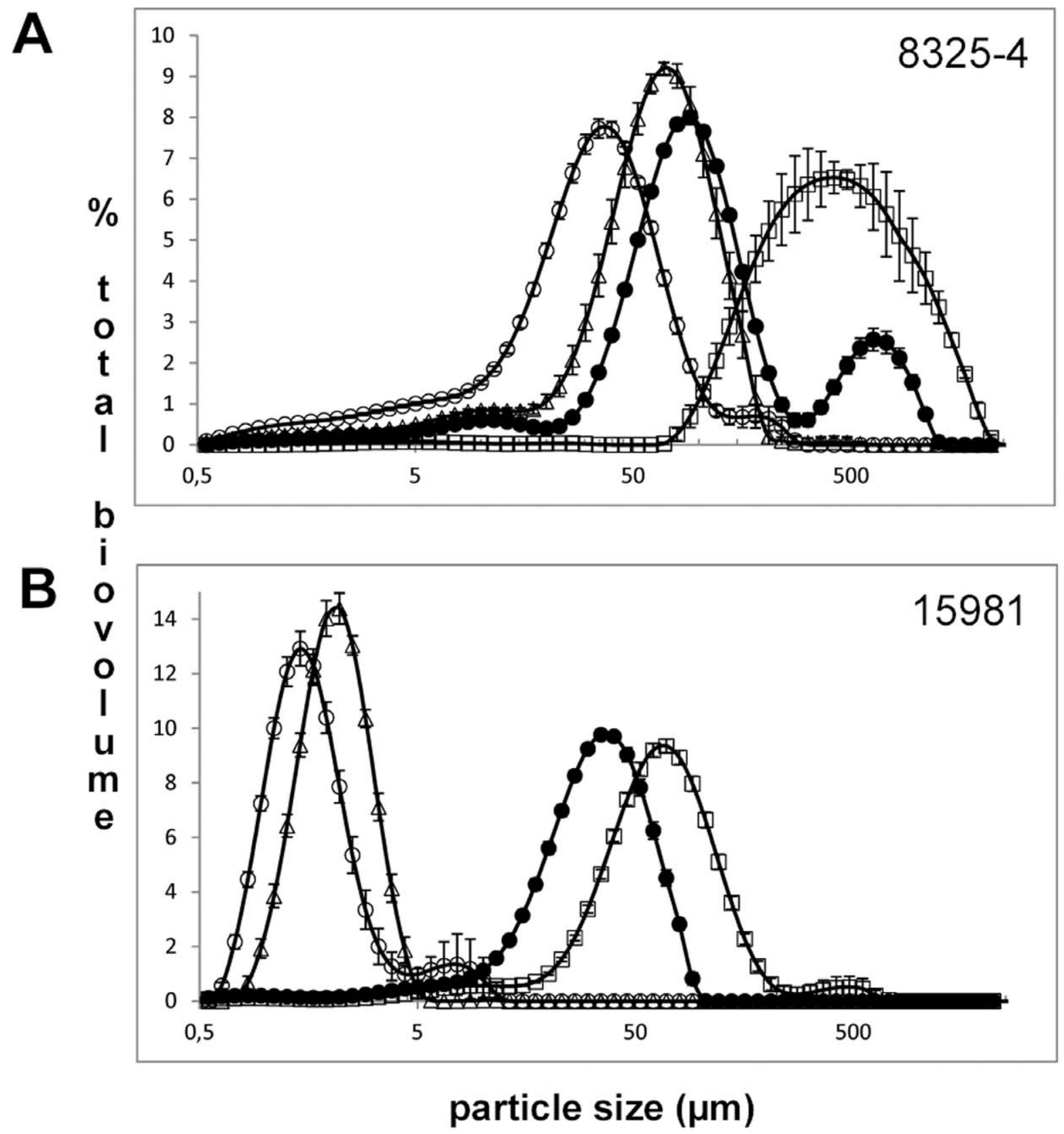

Figure 4. Aggregation is influenced by the presence of sub-inhibitory concentrations of antibiotics. $8325-4$ (panel A) and 15981 (panel B) were cultivated to $\mathrm{OD}_{600}$ of 2 in TSB (solid circle) or in TSB added $1 / 25 \times \mathrm{MIC}$ of erythromycin (open triangles), cefuroxime (open circles) or rifampicin (open squares). The size distribution of planktonic aggregates was examined using LDA. Error bars indicate standard deviation $(n=5)$. doi:10.1371/journal.pone.0041075.g004

aggregation. The conserved ica operon is present in most clinical isolates of $S$. aureus [45] and its expression is induced in exponential growth phase [16,31] and during infection [16]. Furthermore, clinical data show that $S$. aureus form PIA embedded multi-cellular aggregates within the mucus of cystic fibrosis patients [45]. Taken together, PIA is likely to contribute to both the aggregation process and the pathogenesis of $S$. aureus.

Although little is still known about the environmental factors that promote aggregation, we observed that different environmental conditions $\left(\mathrm{NaCl}\right.$, glucose, $\mathrm{O}_{2}$ ) affected the aggregation ability of many $S$. aureus sub-species, indicating that aggregation may be a common feature of staphylococci. Interestingly, also sub- inhibitory concentrations of antibiotics affected aggregation. As the effects were correlated with corresponding changes in PIA production we propose that sub-inhibitory concentrations of antibiotics may affect aggregation of $S$. aureus by modulating the PIA production. This may also be the case for other staphylococcal species as antibiotics have been shown to stimulate ica expression in Staphylococcus epidermidis [47].

The central role of PIA in formation of aggregates and some types of biofilm indicated that the $S$. aureus aggregates may possess properties resembling biofilms. The initial steps involved in biofilm formation and aggregation, however, are likely to be different since fibronectin binding proteins $\mathrm{A}$ and $\mathrm{B}$ promote biofilm 


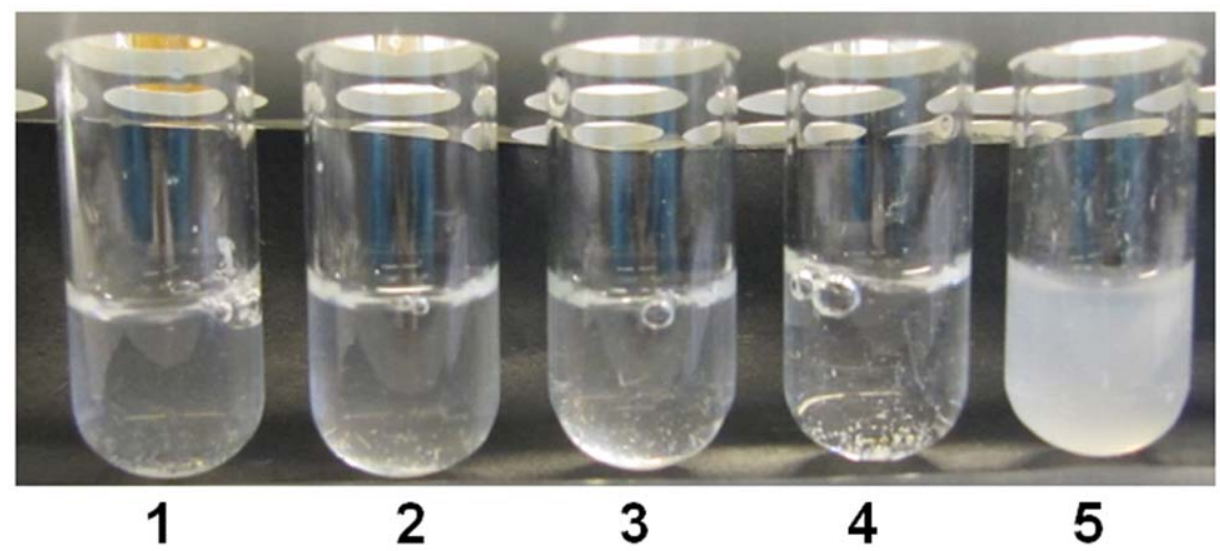

Figure 5. Polysaccharide constitutes the extracellular matrix of 8325-4 aggregates. Aggregates of 8325-4 cells were treated with DNase (tube 2), proteinase $\mathrm{K}$ (tube 3) or sodium metaperiodate (tube 5) at $37^{\circ} \mathrm{C}$ for 18 hours. Tubes 1 and 4 are untreated controls. doi:10.1371/journal.pone.0041075.g005

formation but do not contribute to aggregation. Furthermore, strong biofilm formers such as an agr mutant in 8325-4 and the $r s b U^{+}$complemented SH1000 showed very limited aggregation potential. On the other hand, protein A encoded by spa has previously been shown to promote both biofilm and aggregation of $S$. aureus [12] and supportive of this, we observed that a spa mutation in strain 8325-4 abolished aggregation (results not shown). However, the existence of both PIA-dependent [37] and PIA-independent [48] biofilms may complicate the interpretations of these results. Taken altogether, our results suggest that formation of aggregates and biofilms may not be identical processes.

Biofilms are generally considered to have low metabolic activity [20] and accordingly, we found metabolic activity in surface attached biofilms to be significantly lower than dispersed planktonic cells. However, when we examined the metabolic activity of the non-attached aggregated cells, we unexpectedly found it to be 7-8 fold higher compared to dispersed cells. In biofilms, dead cells have previously been proposed as source a of nutrition for a growing surface layer of cells [48]. Confocal laser scanning microscopy of LIVE/DEAD stained aggregates indeed showed that in analogy to biofilms, cells with low membrane potential dominate the center of these aggregates while a layer of metabolically active cells coat the aggregates, which may explain the increased metabolic activity observed in the aggregated compared to the dispersed cell fraction. Isogenic ica mutants of 8325-4 and 15981 had low levels of metabolic activity, which was comparable to the dispersed cell fraction of the respective wild types emphasizing the significance of the aggregate life style for high metabolic activity. Furthermore, following sonication, cells from disrupted aggregates retained their high metabolic activity and collectively, these results suggest that cells in aggregates are experiencing more growth stimulating conditions than both dispersed and biofilm-dwelling cells.

Another significant hallmark of biofilms is their resistance to antimicrobial compounds [4,6]. Importantly, we found that the $S$. aureus aggregates are tolerant to various antibiotics. The antibiotics have very different cellular targets (protein-, DNA- and cell wall synthesis) indicating that the mechanism conferring the tolerance to the aggregated cells probably is general. Several mechanisms have been suggested to explain the reduced killing of cells in biofilms including reduced penetration of antibiotics into the biofilm, decreased growth rate, persister cells and phenotypic variants [49-52]. In contrast to the aggregates formed by $P$. aeruginosa [24], the $S$. aureus aggregates are highly robust and resistant to substantial shear forces suggesting that the density of the matrix may offer protection against antimicrobial compounds. Indeed, we found that disruption of the aggregates by sonication completely abolished the protection against kanamycin. In accordance with observations in $P$. aeruginosa and Saccharomyces

A

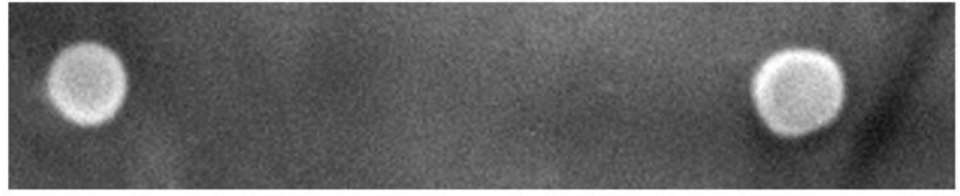

$8325-4$

Newman

SA564

15981

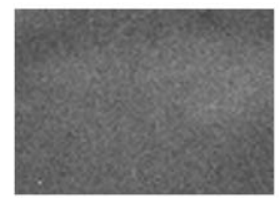

$\Delta i c a$

B

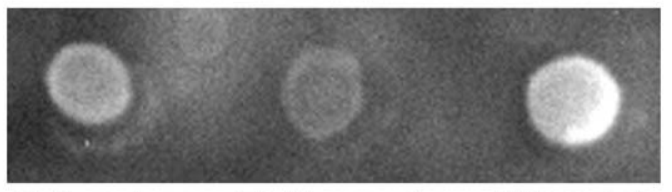

Cefuroxime Erythromycin Rifampicin

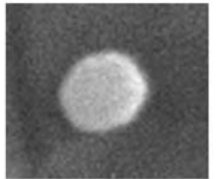

Control

Figure 6. Production of the Polysaccharide Intercellular Adhesin (PIA). Dot blot and immune-detection was used to determine the amount of PIA produced by different strains in post-exponential growth phase (A) or by strain 8325-4 after exposure to $1 / 25$ MIC of different antibiotics (B). doi:10.1371/journal.pone.0041075.g006 

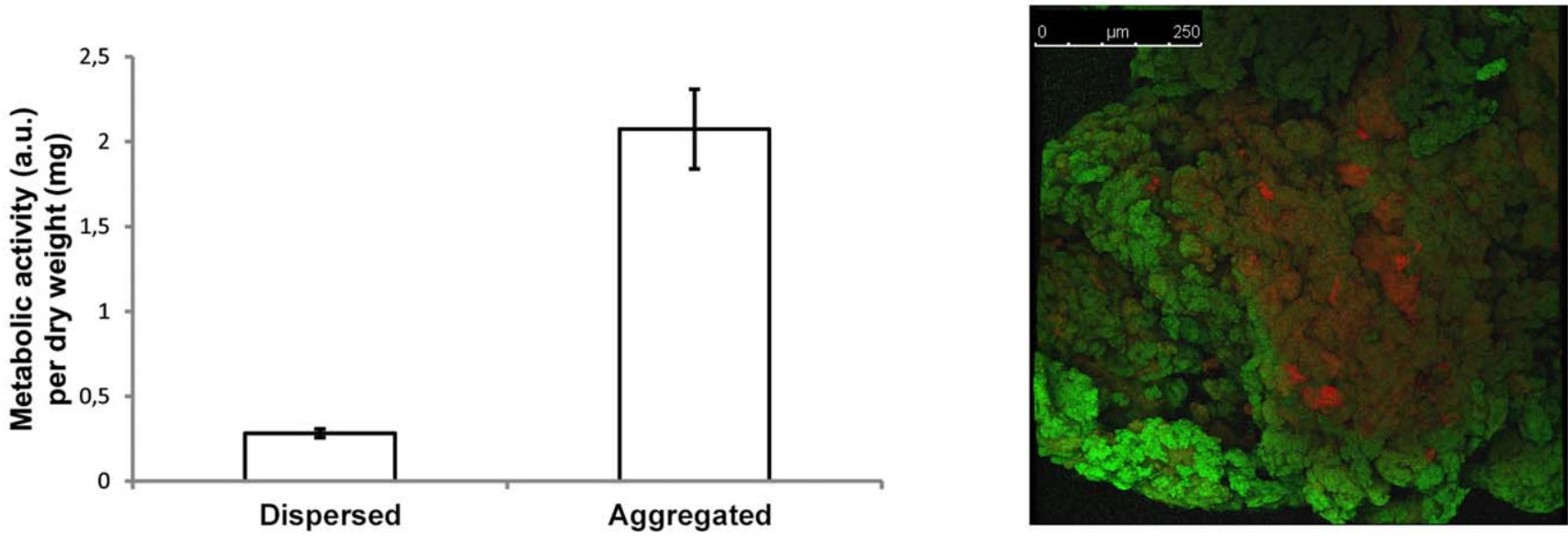

Figure 7. Metabolic activity is significantly higher in aggregated compared to dispersed cells. Metabolic activity was determined in a post-exponential $\left(\mathrm{OD}_{600}=2\right)$ culture of $8325-4$ by measuring reduced XTT (arbitrary units) normalized to mg dry weight $(\mathrm{A})$. Error bars indicate standard deviation $(n=3)$. The distribution of active cells (green) and cells with low membrane potential (red) in aggregates was determined using LIVE/DEAD staining and CLSM (B).

doi:10.1371/journal.pone.0041075.g007

cerevisiae this indicates that protection against antibiotics is a consequence of a physical barrier provided by the aggregates rather than the physiological state of the cells $[24,43]$.

Social behavior is commonly observed for eukaryotic organisms where aggregation appears to be a highly controlled process that reflects adaptive behavior in response to adverse environmental conditions $[43,53]$. Less is known about social behavior in prokaryotic organisms but it is an intriguing speculation that aggregation may be an adaptive response that allows $S$. aureus to withstand host defenses and antimicrobial therapy. The results in this study represent in vitro experiments and studies investigating the clinical impact of the aggregation phenotype are highly warranted. In conclusion, we have shown that $S$. aureus under laboratory conditions is capable of forming large aggregates as a

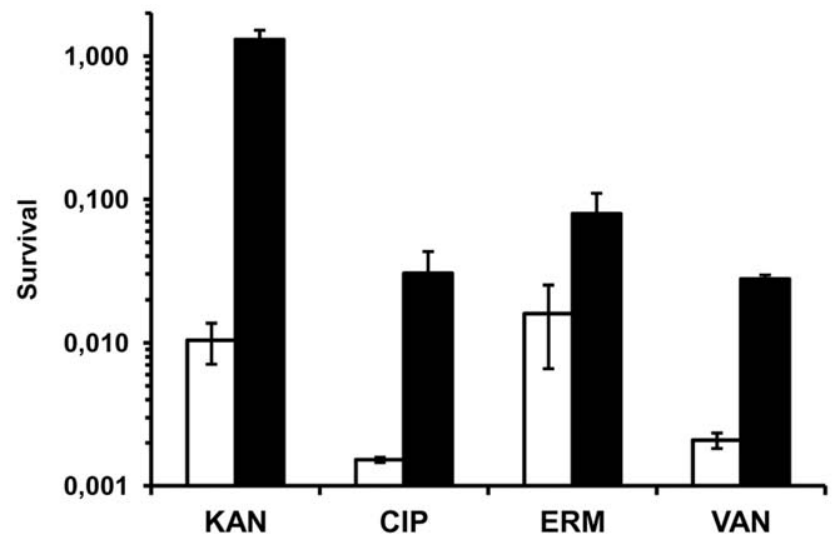

Figure 8. Aggregated cells have increased survival after antibiotic treatment. Cells in aggregates (solid bars) survive better than dispersed cells (open bars) following treatment with $25 \times \mathrm{MIC}$ of kanamycin (KAN), ciprofloxacin (CIP), erythromycin (ERM) or vancomycin (VAN). Survival was calculated as CFU present in the aggregate and dispersed fractions after treatment with antibiotics relative to CFU measured before antibiotic exposure. Error bars indicate standard deviation $(n=3)$.

doi:10.1371/journal.pone.0041075.g008 consequence of enhanced production of the PIA polysaccharide. We demonstrate similarities to surface bound biofilms including an increased tolerance towards antibiotics, and we speculate that aggregates due to the biofilm-like properties combined with mobility may be of significant clinical importance.

\section{Materials and Methods}

\section{Bacterial Strains and Culture Conditions}

The bacterial strains and plasmids used in this study are listed in Table 1. Strains were grown in tryptic soy broth (TSB; Oxoid) or on tryptic soy agar (TSA; Oxoid). Under standard growth conditions cultures were grown in Erlenmeyer flasks with an air:TSB volume ratio of 10:1. TSB was inoculated with cells from TSA plates to $\mathrm{OD}_{600}$ of 0.01 and incubated at $37^{\circ} \mathrm{C}$ with agitation (160 rpm) until visible aggregation occurred in late exponential phase (approx. $4 \mathrm{~h}$ growth). When appropriate, $2 \% \mathrm{NaCl}, 35 \mathrm{mM}$ glucose was supplemented to the TSB. For reduced $\mathrm{O}_{2}$ exposure, cultures were grown in tightly sealed Erlenmeyer flasks to prevent air exchange. Biofilm formation experiments were performed in TSB supplemented with $35 \mathrm{mM}$ glucose in Erlenmeyer flasks incubated at $37^{\circ} \mathrm{C}$ with no agitation. If sonication was applied before plating, cells were suspended in $1 \mathrm{ml} 0.9 \% \mathrm{NaCl}$ or TSB and sonicated 15 pulses, $500 \mathrm{msec}, 50 \%$ power using a Bandelin sonopuls HD2070/UW2070 (Bandelin electronics, Germany) apparatus. Large aggregates sedimented quickly when shaking was stopped and therefore care was taken to manually agitate the flasks to ensure an even distribution of aggregates in the flasks immediately before sampling. All cultures containing aggregates were handled using pipette tips with minimum $2.5 \mathrm{~mm}$ opening to prevent shearing of the aggregates.

\section{LDA-particle Sizing of Aggregates in Liquid Cultures}

Laser-diffraction analysis was performed essentially as reported previously [23] (Text S1). As our standard condition on the Malvern Mastersizer 2000 instrument we used a low stirring speed of $50 \mathrm{rpm}$ and pump speed of $250 \mathrm{rpm}$, which kept aggregates in suspension and ensured an even flow of aggregates into the detection chamber while still keeping shear forces at a minimum. 
Table 1. Strains and plasmids used in the study.

\begin{tabular}{|c|c|c|}
\hline Strains and plasmids & Relevant characteristics & Source and reference \\
\hline \multicolumn{3}{|l|}{ Strains } \\
\hline $8325-4$ & Wild type strain 8325 cured of phages $\phi 11, \phi 12$ and $\phi 13$ & {$[55]$} \\
\hline RN4220 & Restriction-defective derivative of RN450 & {$[56]$} \\
\hline SH1000 & Functional $r s b U$ derivative of $8325-4 r s b U^{+}$ & [57] \\
\hline 15981 & Clinical strain & [58] \\
\hline Newman & Clinical isolate (ATCC 25904) & [59] \\
\hline SA564 & Low passage clinical isolate from a patient with toxic shock syndrome & {$[60]$} \\
\hline ATC35556 4 ica::tet & Does not produce PNAG/PIA & [13] \\
\hline 8325-4Aica::tet & Transduced from ATC35556 $\Delta$ ica::tet & This study \\
\hline 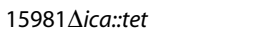 & Does not produce PNAG/PIA & {$[61]$} \\
\hline DU5723 & Protein A negative strain derivative of $8325-4$ & [63] \\
\hline RN6911 & 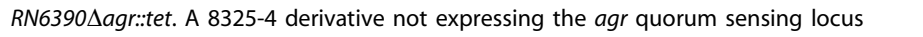 & {$[62]$} \\
\hline 8325-4-pRMC2 & $8325-4$ harbouring $\mathrm{pRMC2}$ & This study \\
\hline 8325-4-rifR & Spontaneous rifampicin resistant mutant of $8325-4$ & This study \\
\hline 8325-4-CFP & 8325-4 harbouring PJEBAN2 & This study \\
\hline 8325-4-YFP & 8325-4 harbouring PJEBAN3 & This study \\
\hline \multicolumn{3}{|l|}{ Plasmids } \\
\hline PJEBAN2 & EmR, Mob+(IncP), oriR pAM $\beta 1$, oriR pUC; Pdlt-cfp+ & {$[33]$} \\
\hline PJEBAN3 & EmR, Mob+(IncP), oriR pAM $\beta 1$, oriR pUC; Pdlt-yfp+ & {$[33]$} \\
\hline pRMC2 & cat, bla; tetR,Pxyl/tet (1xtetO),E. coli/Staphylococcus shuttle vector, pALC2073 derivative & {$[64]$} \\
\hline
\end{tabular}

As the cell populations of both of the non-aggregating strains (Newman and SA564) were in the size fraction $<6 \mu \mathrm{m}$, we used this value as the cut-off to distinguish between dispersed cell and aggregate fractions.

\section{Procedure for Separation of Aggregates from Dispersed Cells}

Ten $\mathrm{mL}$ culture was aliquoted into a $12 \mathrm{~mL}$ Falcon tube and aggregates were allowed to sediment for $10 \mathrm{~min}$ before a quick spin of $1400 \mathrm{rpm}, 15 \mathrm{~s}$ was applied. The separation procedure is a compromise since it was not possible to pellet all aggregates while keeping dispersed cells in suspension. Therefore, the length and speed of the quick spin step was calibrated to yield no visible cell pellet using a fully dispersed culture of a non-aggregating strain but a visible pellet when applied to an aggregating culture. When analyzing the supernatant after the quick spin procedure of such a culture it was revealed that all large aggregates $(>50 \mu \mathrm{m})$ were removed and the majority of the cells were in the size fraction between single cells $(1 \mu \mathrm{m})$ and $15 \mu \mathrm{m}$ (Figure S5).

\section{Fluorescent Tagging of $S$. aureus}

Standard $S$. aureus transformation procedure was used by first amplifying PJEBAN3 in RN4220 $\left(\mathrm{R}^{-/} \mathrm{M}^{+}\right)$before electroporating it into 8325-4 followed by selective plating on TSA plates containing $5 \mu \mathrm{g} / \mathrm{ml}$ erythromycin to obtain 8325-4 expressing yellow fluorescent protein (YFP). The same procedure was used to introduce PJEBAN2 into 8325-4 to obtain cells expressing the cyan fluorescent protein (CFP). However, the CFP signal was not detectable in this strain and thus the strain carrying PJEBAN2 was used as control in studies with mixed cultures.

\section{Microscopy of Aggregates}

Prior to CLSM microscopy of non-fluorescent cellular aggregates cells were stained using LIVE/DEAD ${ }^{\circledR}$ Baclight ${ }^{\text {TM }}$ Bacterial Viability Kit (Invitrogen) according to the manufacturers' recommendations.

Confocal laser scanning microscopy was carried out using a Leica SP5-X confocal laser scanning microscope (CLSM), equipped with an argon and white light laser for excitation of the flourophores (excitation/emission): SYTO 9 (480 nm/ $500 \mathrm{~nm})$, propidium iodide $(490 \mathrm{~nm} / 635 \mathrm{~nm})$ and YFP $(514 \mathrm{~nm} / 565 \mathrm{~nm})$. Images were obtained by overlaying either 2 fluorescent channels alone or in combination with a transmission (brightfield) channel. All images were generated and processed using the LAS AF version 2.3.5 (Leica Microsystems, Germany).

Scanning Electron Microscopy (SEM) was performed as previously described [54]. In short, aggregates were fixed in $2 \%$ glutaraldehyde and postfixed in $1 \% \mathrm{OsO}_{4}$. Samples were then dehydrated in ethanol, critical point-dried using $\mathrm{CO}_{2}$, and sputtercoated with gold according to standard procedures. Samples were investigated using a Philips XL Feg30 scanning electron microscope operated at $5 \mathrm{kV}$ accelerating tension.

\section{Degradation of Planktonic Aggregates}

Aggregates were separated from dispersed cells before being resuspended in $500 \mu \mathrm{l} 50 \mathrm{mM}$ sodium acetate buffer $(\mathrm{pH} 4.5)$ and added $250 \mu \mathrm{l} 10 \mathrm{mM}$ sodium metaperiodate (Sigma) or in $500 \mu \mathrm{l}$ Tris with $100 \mathrm{mM} \mathrm{NaCl}(\mathrm{pH}$ 7.5) and added either $100 \mu \mathrm{l}$ DNase $1 \mathrm{U} / \mu \mathrm{l}$ (Fermentas) or $250 \mu \mathrm{l} 100 \mu \mathrm{g} / \mathrm{ml}$ proteinase $\mathrm{K}$ (Sigma). Samples were incubated at $37^{\circ} \mathrm{C}$ for 18 hours. 
Dot Blot Analysis of PIA Level

The PIA level in $S$. aureus strains was detected as described by Cramton et al., 1999 with few modifications [13] (Text S1).

\section{Metabolic Activity}

A colorimetric assay in which the colorless XTT (2,3-bis-(2methoxy-4-nitro-5-sulfophenyl)-2H-tetrazolium-5-carboxanilide) (Sigma) is reduced to the water soluble formazan dye by metabolically active cells was used to compare the metabolic activity between biofilm cells, aggregated cells and dispersed cells basically as described before $[40,41]$. Biofilm was scraped off the glass surface of Erlenmeyer flasks following two times rinsing with $0.01 \mathrm{M}$ PBS (pH 7.4) and from liquid cultures, the dispersed cell and aggregate fractions were separated and harvested. From each of the three fractions 2-10 mg cell mass was resuspended in $500 \mu \mathrm{l}$ of a filter-sterilized $0.5 \mathrm{mg} / \mathrm{ml} \mathrm{XTT}$ and $50 \mu \mathrm{M}$ menadione (sigma) solution. Following $3 \mathrm{~h}$ incubation $\left(37^{\circ} \mathrm{C}, 160 \mathrm{rpm}\right.$ agitation) in the dark, the cells were harvested and reduction of XTT was measured in the supernatant at $492 \mathrm{~nm}$ using an eppendorf BioPhotometer Plus spectrophotometer. The pelleted cells were dried $\left(55^{\circ} \mathrm{C}, 18 \mathrm{~h}\right)$ to determine the dry weight. A standard curve revealed a linear relationship between dry weight and XTT reduction from at least 1 to $13 \mathrm{mg}$ of dry weight cell mass (data not shown).

\section{Mutation Frequency}

Aggregating cultures were separated into aggregate and dispersed cell fractions. Both fractions were centrifuged and resuspended in $1 \mathrm{ml}$ TSB. Cells were sonicated using 15 pulses, $500 \mathrm{msec}, 50 \%$ power and $\mathrm{OD}_{600}$ was adjusted to 3. Cells were plated on TSA with $0.1 \mu \mathrm{g} / \mathrm{ml}$ rifampicin to estimate the number of spontaneous rifampicin-resistant mutants in the two fractions. Furthermore, cells were plated on TSA to estimate total CFU in the two fractions and mutation frequency was calculated as the number of rifampicin-resistant mutants per total CFU.

\section{MIC Determination}

Cells were inoculated in TSB with added antibiotics to an $\mathrm{OD}_{600}$ of 0.01 and incubated at $37^{\circ} \mathrm{C}$. The assay was performed in 96 well microtiter plates (100 $\mu$ l culture per well). The MIC was defined as the lowest concentration from 2-fold dilution series of a given antibiotic that prevented growth. The following MICs were estimated: cefuroxime $(\mathrm{CXM})=4 \mu \mathrm{g} / \mathrm{ml}$, erythromycin $(\mathrm{ERM})=0.25 \mu \mathrm{g} / \mathrm{ml}$, rifampicin $(\mathrm{RIF})=0.032 \mu \mathrm{g} / \mathrm{ml}$, vancomycin $(\mathrm{VAN})=2 \mu \mathrm{g} / \mathrm{ml}$, kanamycin $(\mathrm{KAN})=0.8 \mu \mathrm{g} / \mathrm{ml}$ and ciprofloxacin $(\mathrm{CIP})=1 \mu \mathrm{g} / \mathrm{ml}$. MIC did not vary between the strains used in the experiments (data not shown).

\section{Susceptibility to Antibiotics}

Cells from two 8325-4 derivatives resistant to chloramphenicol and rifampicin, respectively were cultivated using standard growth conditions until visible cellular aggregates occurred in both (approx. $4 \mathrm{~h}$ ). Six $\mathrm{ml}$ aggregated culture was separated into aggregate and dispersed cell fractions. Both fractions were washed in TSB and the aggregate fraction from one strain was mixed $(1: 1)$ with the dispersed cell fraction from the other strain pre-adjusted to $\mathrm{OD}_{600}=0.1$. Cultures were re-incubated until $\mathrm{OD}_{600}=0.5$ when $25 \times$ MIC of the antibiotics kanamycin $(\mathrm{KAN})$, ciprofloxacin (CIP), erythromycin (ERM) and vancomycin (VAN) was added. Cultures were harvested after $0 \mathrm{~h}$ (control), $3 \mathrm{~h}$ (KAN and CIP) or $18 \mathrm{~h}$ (ERM and VAN) of incubation with antibiotics, depending on the killing kinetics of the antibiotic applied. To harvest the cells, cultures were separated in aggregated and dispersed cell fractions, centrifuged $(6,300 \mathrm{G}, 5 \mathrm{~min})$ and resuspended in $1 \mathrm{ml} 0.9 \% \mathrm{NaCl}$. Cells were then sonicated (15 pulses, $500 \mathrm{msec}, 50 \%$ power) and plated on TSA; TSA with $10 \mu \mathrm{g} / \mathrm{ml}$ chloramphenicol or TSA with $0.1 \mu \mathrm{g} / \mathrm{ml}$ rifampicin to estimate total CFU, CFU of cells originating from the dispersed cell fraction and CFU originating from the aggregate fraction, respectively. Exponential cultures of the two strains included in the study were equally sensitive to the used antibiotics and had same growth rate (data not shown).

\section{Statistical Analysis}

Averages were compared using two-tailed student's t-test.

\section{Supporting Information}

Figure S1 Aggregates are held together by strong forces. Aggregates from a post-exponential $\left(\mathrm{OD}_{600}=2\right)$ culture of strain 8325-4 were analyzed using LDA. The aggregates were subjected to increasing shear forces (from shear 1 to shear 5) represented by increasing stirrer and pump speed. Error indicate standard deviation $(\mathrm{n}=5)$

(TIF)

Figure S2 Aggregation of 8325-4 derivatives. Post-exponential cultures of 8325-4 derivative strains were investigated by LDA for their ability to aggregate. Error bars indicate standard deviation $(\mathrm{n}=5)$

(TIF)

Figure S3 Metabolic activity in biofilm and ica mutants. Metabolic activity was determined and normalized to $\mathrm{mg}$ dry weight in (A): an overnight culture of $8325-4$ by measuring reduced XTT (arbitrary units) of dispersed cells and dislodged biofilm or (B): dispersed and aggregated cells of wild type 8325-4 and 15981 as well as their isogenic ica mutants. Error bars indicate standard deviation $(\mathrm{n}=3)$.

(TIF)

Figure S4 Mutation frequency is increased in aggregating cells. The aggregate fraction of a post-exponential 8325-4 culture was separated from the dispersed fraction. Mutation frequency was calculated as the number of rifampicin resistant mutants per total CFU. Error bars indicate standard deviation $(\mathrm{n}=3)$.

(TIF)

Figure S5 Quickspin removes most aggregates from supernatant. A post-exponential culture of 8325-4 containing visible aggregates was subjected to the quick spin procedure (centrifugation $1400 \mathrm{rpm}, 15 \mathrm{~s}$ ) and the supernatant was analyzed using LDA. All aggregates $>50 \mu \mathrm{m}$ were removed and the majority of the cells were present in the $1-15 \mu \mathrm{m}$ size range. Error bars represent standard deviation $(\mathrm{n}=5)$.

(TIF)

Text S1 Supporting information, materials and methods. Description of the LDA method and immune-detection method.

(DOCX)

\section{Acknowledgments}

We thank Gerald Pier (Harvard Medical School) for the generous gift of the PIA/PNAG antibody and Friedrich Götz (University of Tübingen), Greg Somerville (University of Nebraska), Simon Foster (University of Sheffield), Markus Bischoff (University of Saarland Hospital) and Iñigo Lasa (University of Navarra) for providing strains. We thank Christel G. 
Buerholt, Vi Phuong Thi Nguyen, Piotr Binczyzki, Klaus Qvortrup and Zhila Nikrozi for help with carrying out experiments.

\section{References}

1. Costerton JW, Stewart PS, Greenberg EP (1999) Bacterial biofilms: a common cause of persistent infections. Science 284: 1318-1322.

2. Otto M (2008) Staphylococcal biofilms. Curr Top Microbiol Immunol 322: 207228.

3. Brady RA, Leid JG, Calhoun JH, Costerton JW, Shirtliff ME (2008) Osteomyelitis and the role of biofilms in chronic infection. FEMS Immunol Med Microbiol 52: 13-22.

4. del Pozo JL, Patel R (2007) The challenge of treating biofilm-associated bacterial infections. Clin Pharmacol Ther 82: 204-209.

5. Thurlow LR, Hanke ML, Fritz T, Angle A, Aldrich A, et al. (2011) Staphylococcus aureus biofilms prevent macrophage phagocytosis and attenuate inflammation in vivo. J Immunol 186: 6585-6596.

6. Nadell CD, Xavier JB, Foster KR (2009) The sociobiology of biofilms. FEMS Microbiol Rev 33: 206-224.

7. Rice KC, Mann EE, Endres JL, Weiss EC, Cassat JE, et al. (2007) The cidA murein hydrolase regulator contributes to DNA release and biofilm development in Staphylococcus aureus. Proc Natl Acad Sci U S A 104: 8113-8118.

8. Izano EA, Amarante MA, Kher WB, Kaplan JB (2008) Differential roles of poly$\mathrm{N}$-acetylglucosamine surface polysaccharide and extracellular DNA in Staphylococcus aureus and Staphylococcus epidermidis biofilms. Appl Environ Microbiol 74: 470-476.

9. Mann EE, Rice KC, Boles BR, Endres JL, Ranjit D, et al. (2009) Modulation of eDNA release and degradation affects Staphylococcus aureus biofilm maturation. PLoS ONE 4: e5822.

10. Rice KC, Firek BA, Nelson JB, Yang SJ, Patton TG, et al. (2003) The Staphylococcus aureus cidAB operon: evaluation of its role in regulation of murein hydrolase activity and penicillin tolerance. J Bacteriol 185: 2635-2643.

11. Vergara-Irigaray M, Valle J, Merino N, Latasa C, Garcia B, et al. (2009) Relevant role of fibronectin-binding proteins in Staphylococcus aureus biofilmassociated foreign-body infections. Infect Immun 77: 3978-3991.

12. Merino N, Toledo-Arana A, Vergara-Irigaray M, Valle J, Solano G (2009) Protein A-mediated multicellular behavior in Staphylococcus aureus. J Bacteriol 191: 832-843.

13. Cramton SE, Gerke C, Schnell NF, Nichols WW, Gotz F (1999) The intercellular adhesion (ica) locus is present in Staphylococcus aureus and is required for biofilm formation. Infect Immun 67: 5427-5433.

14. Gotz F (2002) Staphylococcus and biofilms. Mol Microbiol 43: 1367-1378.

15. McKenney D, Hubner J, Muller E, Wang Y, Goldmann DA, et al. (1998) The ica locus of Staphylococcus epidermidis encodes production of the capsular polysaccharide/adhesin. Infect Immun 66: 4711-4720.

16. Fluckiger U, Ulrich M, Steinhuber A, Doring G, Mack D, et al. (2005) Biofilm formation, icaADBC transcription, and polysaccharide intercellular adhesin synthesis by staphylococci in a device-related infection model. Infect Immun 73: $1811-1819$

17. Aaron SD, Ferris W, Ramotar K, Vandemheen K, Chan F, et al. (2002) Single and combination antibiotic susceptibilities of planktonic, adherent, and biofilmgrown Pseudomonas aeruginosa isolates cultured from sputa of adults with cystic fibrosis. J Clin Microbiol 40: 4172-4179.

18. Parsek MR, Singh PK (2003) Bacterial biofilms: an emerging link to disease pathogenesis. Annu Rev Microbiol 57: 677-701.

19. Hoyle BD, Costerton JW (1991) Bacterial resistance to antibiotics: the role of biofilms. Prog Drug Res 37: 91-105.

20. Anderson GG, O'Toole GA (2008) Innate and induced resistance mechanisms of bacterial biofilms. Curr Top Microbiol Immunol 322: 85-105.

21. Bjarnsholt T, Jensen PO, Burmolle M, Hentzer M, Haagensen JA, et al. (2005) Pseudomonas aeruginosa tolerance to tobramycin, hydrogen peroxide and polymorphonuclear leukocytes is quorum-sensing dependent. Microbiology 151: 373-383.

22. Aendekerk S, Diggle SP, Song Z, Hoiby N, Cornelis P, et al. (2005) The MexGHI-OpmD multidrug efflux pump controls growth, antibiotic susceptibility and virulence in Pseudomonas aeruginosa via 4-quinolone-dependent cell-tocell communication. Microbiology 151: 1113-1125.

23. Schleheck D, Barraud N, Klebensberger J, Webb JS, McDougald D, et al. (2009) Pseudomonas aeruginosa $\mathrm{PAO} 1$ preferentially grows as aggregates in liquid batch cultures and disperses upon starvation. PLoS ONE 4: e5513.

24. Alhede M, Kragh KN, Qvortrup K, Allesen-Holm M, van Gennip M, et al. (2011) Phenotypes of Non-Attached Pseudomonas aeruginosa Aggregates Resemble Surface Attached Biofilm. PLoS One 6: e27943.

25. Bjarnsholt T, Jensen PO, Fiandaca MJ, Pedersen J, Hansen CR, et al. (2009) Pseudomonas aeruginosa biofilms in the respiratory tract of cystic fibrosis patients. Pediatr Pulmonol 44: 547-558.

26. Burmolle M, Thomsen TR, Fazli M, Dige I, Christensen L, et al. (2010) Biofilms in chronic infections - a matter of opportunity - monospecies biofilms in multispecies infections. FEMS Immunol Med Microbiol 59: 324-336. FIM714 [pii];10.1111/j.1574-695X.2010.00714.x [doi].

\section{Author Contributions}

Conceived and designed the experiments: MTC JH HI. Performed the experiments: MTG JH. Analyzed the data: MTA JH DF HI. Contributed reagents/materials/analysis tools: TJA. Wrote the paper: MTAJH DF HI.

27. Andersen MT, Brondsted L, Pearson BM, Mulholland F, Parker M, et al. (2005) Diverse roles for HspR in Campylobacter jejuni revealed by the proteome, transcriptome and phenotypic characterization of an hspR mutant. Microbiology 151: 905-915.

28. Cohn MT, Ingmer H, Mulholland F, Jorgensen K, Wells JM, et al. (2007) Contribution of conserved ATP-dependent proteases of Campylobacter jejuni to stress tolerance and virulence. Appl Environ Microbiol 73: 7803-7813.

29. Frick IM, Morgelin M, Bjorck L (2000) Virulent aggregates of Streptococcus pyogenes are generated by homophilic protein-protein interactions. Mol Microbiol 37: 1232-1247.

30. Mirani ZA, Jamil N (2010) Effect of sub-lethal doses of vancomycin and oxacillin on biofilm formation by vancomycin intermediate resistant Staphylococcus aureus. J Basic Microbiol.

31. Seidl K, Goerke C, Wolz C, Mack D, Berger-Bachi B, et al. (2008) Staphylococcus aureus CcpA affects biofilm formation. Infect Immun 76: 2044-2050.

32. van Gennip M, Christensen LD, Alhede M, Qvortrup K, Jensen PO, et al. (2012) Interactions between polymorphonuclear leukocytes and P. aeruginosa biofilms on silicone implants in vivo. Infect Immun. IAI.06215-11 [pii];10.1128/ IAI.06215-11 [doi].

33. Andersen JB, Roldgaard BB, Lindner AB, Christensen BB, Licht TR (2006) Construction of a multiple fluorescence labelling system for use in co-invasion studies of Listeria monocytogenes. BMC Microbiol 6: 86.

34. Davies J, Spiegelman GB, Yim G (2006) The world of subinhibitory antibiotic concentrations. Curr Opin Microbiol 9: 445-453.

35. Kummerer K (2009) Antibiotics in the aquatic environment-a review-part I. Chemosphere 75: 417-434.

36. Chander Y, Kumar K, Goyal SM, Gupta SC (2005) Antibacterial activity of soilbound antibiotics. J Environ Qual 34: 1952-1957.

37. Heilmann C, Schweitzer O, Gerke C, Vanittanakom N, Mack D, et al. (1996) Molecular basis of intercellular adhesion in the biofilm-forming Staphylococcus epidermidis. Mol Microbiol 20: 1083-1091.

38. Conibear TC, Collins SL, Webb JS (2009) Role of mutation in Pseudomonas aeruginosa biofilm development. PLoS One 4: e6289.

39. Allegrucci M, Sauer K (2008) Formation of Streptococcus pneumoniae nonphase-variable colony variants is due to increased mutation frequency present under biofilm growth conditions. J Bacteriol 190: 6330-6339.

40. Tunney MM, Ramage G, Field TR, Moriarty TF, Storey DG (2004) Rapid colorimetric assay for antimicrobial susceptibility testing of Pseudomonas aeruginosa. Antimicrob Agents Chemother 48: 1879-1881.

41. Smith K, Perez A, Ramage G, Gemmell CG, Lang S (2009) Comparison of biofilm-associated cell survival following in vitro exposure of meticillin-resistant Staphylococcus aureus biofilms to the antibiotics clindamycin, daptomycin, linezolid, tigecycline and vancomycin. Int J Antimicrob Agents 33: 374-378.

42. Xu KD, Stewart PS, Xia F, Huang CT, McFeters GA (1998) Spatial physiological heterogeneity in Pseudomonas aeruginosa biofilm is determined by oxygen availability. Appl Environ Microbiol 64: 4035-4039.

43. Smukalla S, Caldara M, Pochet N, Beauvais A, Guadagnini S, et al. (2008) FLO1 is a variable green beard gene that drives biofilm-like cooperation in budding yeast. Cell 135: 726-737.

44. Goerke C, Wolz C (2004) Regulatory and genomic plasticity of Staphylococcus aureus during persistent colonization and infection. Int J Med Microbiol 294: 195-202.

45. Goerke C, Wolz C (2010) Adaptation of Staphylococcus aureus to the cystic fibrosis lung. Int J Med Microbiol 300: 520-525.

46. Fazli M, Bjarnsholt T, Kirketerp-Moller K, Jorgensen B, Andersen AS, et al. (2009) Nonrandom distribution of Pseudomonas aeruginosa and Staphylococcus aureus in chronic wounds. J Clin Microbiol 47: 4084-4089.

47. Rachid S, Ohlsen K, Witte W, Hacker J, Ziebuhr W (2000) Effect of subinhibitory antibiotic concentrations on polysaccharide intercellular adhesin expression in biofilm-forming Staphylococcus epidermidis. Antimicrob Agents Chemother 44: 3357-3363.

48. Resch A, Fehrenbacher B, Eisele K, Schaller M, Gotz F (2005) Phage release from biofilm and planktonic Staphylococcus aureus cells. FEMS Microbiol Lett 252: 89-96.

49. Pamp SJ, Gjermansen M, Johansen HK, Tolker-Nielsen T (2008) Tolerance to the antimicrobial peptide colistin in Pseudomonas aeruginosa biofilms is linked to metabolically active cells, and depends on the pmr and mexAB-oprM genes. Mol Microbiol 68: 223-240.

50. Lewis K (2001) Riddle of biofilm resistance. Antimicrob Agents Chemother 45: 999-1007.

51. Mah TF, O’Toole GA (2001) Mechanisms of biofilm resistance to antimicrobial agents. Trends Microbiol 9: 34-39.

52. Stewart PS (2002) Mechanisms of antibiotic resistance in bacterial biofilms. Int J Med Microbiol 292: 107-113. 
53. Queller DC, Ponte E, Bozzaro S, Strassmann JE (2003) Single-gene greenbeard effects in the social amoeba Dictyostelium discoideum. Science 299: 105-106.

54. Qvortrup K, Rostgaard J, Bretlau P (1995) Surface morphology of the endolymphatic duct in the rat. A scanning electron microscopy study. Ann Otol Rhinol Laryngol 104: 120-126.

55. Novick R (1967) Properties of a cryptic high-frequency transducing phage in Staphylococcus aureus. Virology 33: 155-166.

56. Kreiswirth BN, Lofdahl S, Betley MJ, O'Reilly M, Schlievert PM, et al. (1983) The toxic shock syndrome exotoxin structural gene is not detectably transmitted by a prophage. Nature 305: 709-712.

57. Horsburgh MJ, Aish JL, White IJ, Shaw L, Lithgow JK, et al. (2002) sigmaB modulates virulence determinant expression and stress resistance: characterization of a functional rsbU strain derived from Staphylococcus aureus 8325-4. J Bacteriol 184: 5457-5467.

58. Valle J, Toledo-Arana A, Berasain C, Ghigo JM, Amorena B, et al. (2003) SarA and not sigmaB is essential for biofilm development by Staphylococcus aureus. Mol Microbiol 48: 1075-1087.
59. Duthie ES, Lorenz LL (1952) Staphylococcal coagulase; mode of action and antigenicity. J Gen Microbiol 6: 95-107.

60. Somerville GA, Chaussee MS, Morgan CI, Fitzgerald JR, Dorward DW, et al. (2002) Staphylococcus aureus aconitase inactivation unexpectedly inhibits postexponential-phase growth and enhances stationary-phase survival. Infect Immun 70: 6373-6382.

61. Toledo-Arana A, Merino N, Vergara-Irigaray M, Debarbouille M, Penades JR, et al. (2005) Staphylococcus aureus develops an alternative, ica-independent biofilm in the absence of the arlRS two-component system. J Bacteriol 187: 5318-5329.

62. Novick RP, Ross HF, Projan SJ, Kornblum J, Kreiswirth B, et al. (1993) Synthesis of staphylococcal virulence factors is controlled by a regulatory RNA molecule. EMBO J 12: 3967-3975.

63. Patel AH, Nowlan P, Weavers ED, Foster T (1987) Virulence of protein Adeficient and alpha-toxin-deficient mutants of Staphylococcus aureus isolated by allele replacement. Infect Immun 55: 3103-3110.

64. Corrigan RM, Foster TJ (2009) An improved tetracycline-inducible expression vector for Staphylococcus aureus. Plasmid 61: 126-129. 